\title{
A CHRONOLOGY OF THERMAL INK-JET STRUCTURES
}

\author{
Christopher C. Beatty \\ Hewlett-Packard Ink-jet Supplies Business Unit
}

Corvallis, Oregon 97330

\begin{abstract}
Over the past dozen years, thermal inkjet (TIJ) pens have become one of the largest businesses based on micromachining technology. The basic functioning of an inkjet pen is discussed and four generations of mircostructures from the leading manufacturer are examined. Future trends are analyzed including nozzle count and drop volume.
\end{abstract}

\section{INTRODUCTION}

Before discussing the evolution of the TIJ microstructures, a discussion of the basics of the firing mechanism common to all of them is in order. A two-dimensional view of the firing sequence can be seen in Figure 1. These plots come from computational fluid dynamics simulations of the original TIJ architecture.

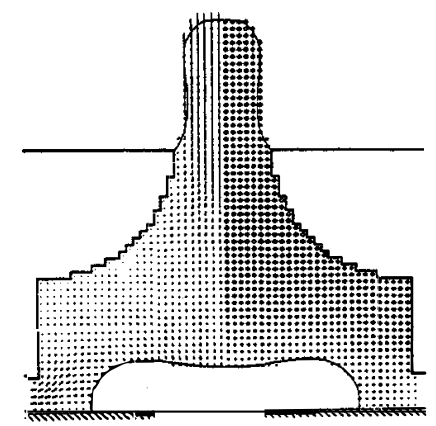

Figure la. TIJ firing sequence at five microseconds

Firing begins with an electrical pulse sent to a thin-film heater at the base of a chamber filled with ink. The pulse is typically only a few microseconds long, but superheats a thin boundary layer of ink to approximately $250^{\circ} \mathrm{C}$.

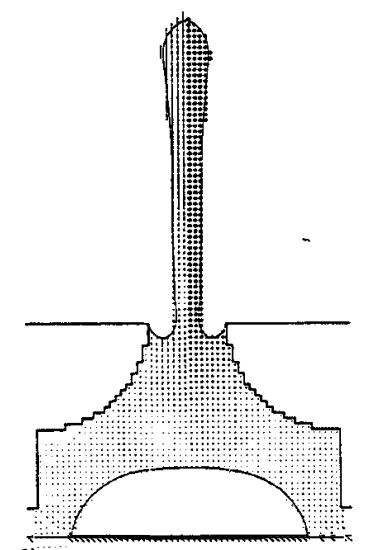

Figure $1 b . T I J$ firing sequence at fifteen microseconds
This causes homogeneous or nearly homogeneous boiling across the surface of the heater. This bubble is referred to as a "drive bubble" since it pushes the ink out of the chamber. After five microseconds, the pulse is complete and the bubble has partially formed and has begun to expel ink out of the orifice. Some ink is also pushed out of the refill channels, but geometries are constructed to minimize this. At fifteen microseconds (figure $1 \mathrm{~b}$ ), the bubble has fully formed and the droplet is being ejected. The tail of the drop has not yet separated. Figure lc shows the collapse of the bubble and the beginning of the refill process at 24 microseconds. The collapse of the bubble cause a tremendous pressure pulse on the thin films due to the implosion or cavitation of the bubble. Depending on the geometry of the chamber, an additional 25-50 microseconds are necessary to let the chamber refill and the orifice meniscus settle into a stable position.

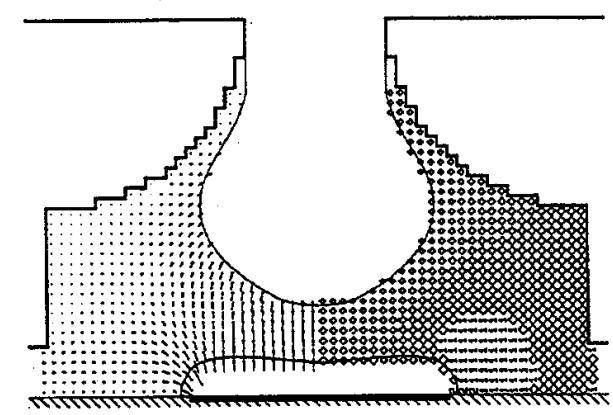

Figure Ic. TIJ firing sequence at twenty-four microseconds.

Figure 2 shows the effect of changing the firing frequency on an inkjet pen. For low frequencies, the firing is completed and the ink has settled back to the equilibrium position for the meniscus. As the frequency is raised, the drop volume decreases because the meniscus is below the equilibrium position.

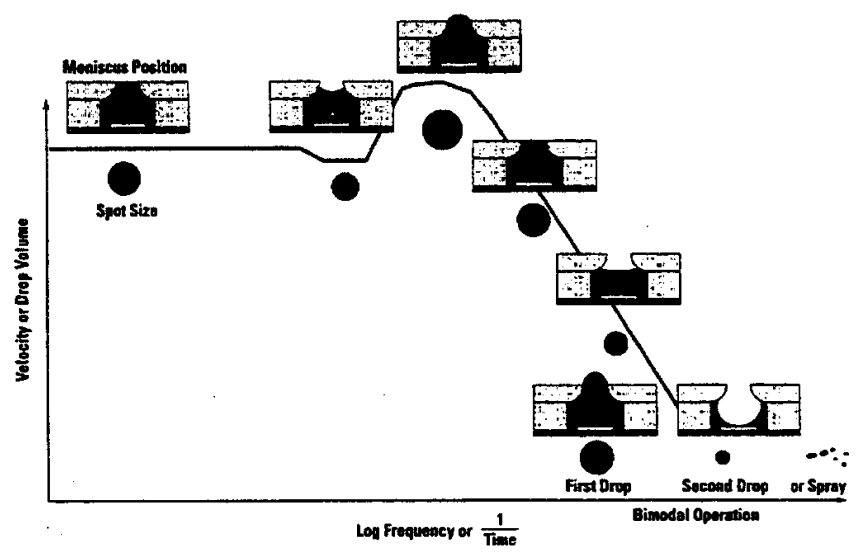

Figure 2. Drop weight versus frequency curve 
Further increase in the frequency actually raises the drop volume because the firing is occurring while the meniscus is bulging outward. Frequencies above this value decrease the drop volume as there is more encroachment into the refill process.

\section{TIJ 1.0}

The first drop-on-demand thermal inkjet pen was successfully commercialized in 1984. It required the merging of several technologies including thin film processing, electroforming and fluidic interconnection.

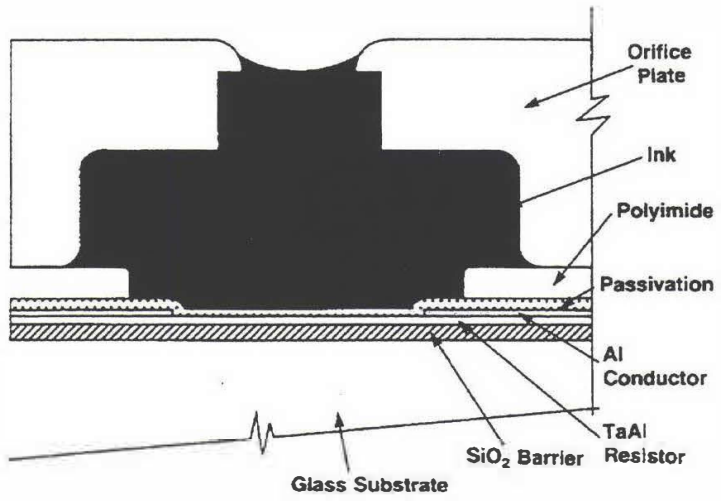

Figure 3. TIJ 1.0 thin-film cross-section.

A cross-section of the TIJ 1.0 firing chamber can be seen in figure 3 . The glass substrate was chosen because it was easily available from another LED fabrication group at the same site and it was thought that silicon would be too expensive. In retrospect, the wide use of silicon substrates and the optimization of equipment for them outweighed the initial cost difference. Despite an insulating substrate, a silicon dioxide layer was sputtered on the glass plate to avoid diffusion of sodium impurities into the metal films which reduced reliability. The resistor heater which is pulsed to fire the pen is made from a sputtered tantalum-aluminum alloy (TaAl). This binary mixture has the unique property of having a nearly zero temperature coefficient of resistance (TCR). This is an important feature to ensure uniform energy delivery during the rapid heating to several hundred degrees Centigrade during a firing event. The resistors are connected to bonding pads with a conventional aluminum alloy. The bonding pads have a thin nickel diffusion barrier and a gold bonding surface.

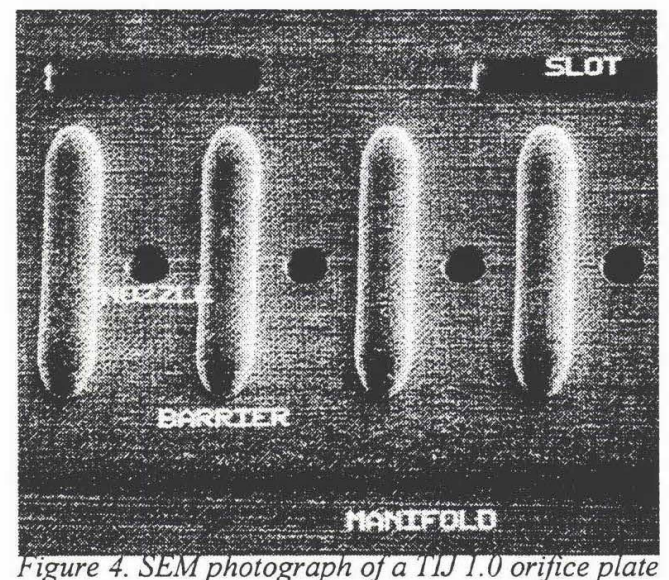

Figure 4. SEM photograph of a TIJ 1.0 orifice plate
The dielectric passivation layer over the heater area protects the metals from the corrosive mixture of ink and high temperature. Silicon carbide provides excellent chemical resistance in this environment, but as a semiconductor it provides an electrical leakage path at higher temperatures. The solution was a dual film dielectric of silicon nitride for electrical isolation and silicon carbide for chemical inertness. The films are deposited sequentially in a plasma-enhanced chemical vapor deposition system (PECVD).

Once the thin film structure is completed, the electroformed nickel orifice plate is attached with a polyimide layer. The orifice plate not only defines the bore for the ejected drop, it also creates barriers between adjacent nozzles to reduce hydraulic crosstalk. A SEM photograph of the TIJ 1.0 orifice plate can be seen in figure 4 .

A typical alphanumeric character produced by the 96 dot per inch (dpi) ThinkJet printer can be seen in figure 5 .

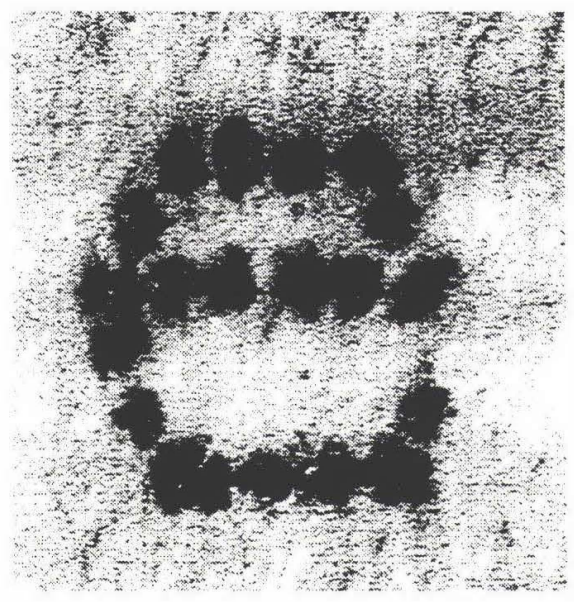

Figure 5. 96 dpi TIJ 1.0 character.

TIJ 2.0

The first entry into the color inkjet market came in 1987. An enhanced monochrome pen was also introduced. This new family was called TIJ 2.0 and several innovations were present.

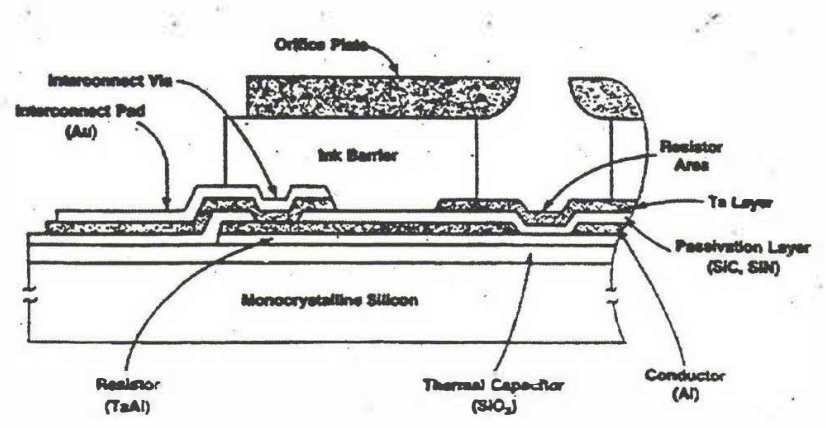

Figure 6. TIJ 2.0 thin-film cross section 


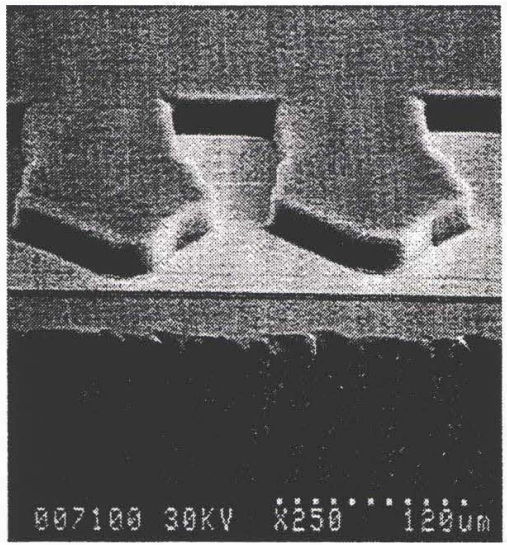

Figure 7. TIJ 2.0 firing chamber without orifice plate.

In the thin film arena, the substrate is a silicon wafer to take advantage of the equipment set and processing knowledge available. A layer of tantalum is present on top of the passivation to withstand the impact of the cavitation when the drive bubble collapses. The toughness of the tantalum provided more than an order of magnitude improvement in the number of cycles the printhead can withstand. Firing chambers can now be shaped into more sophisticated geometries through the use of a photo-imageable polymer layer (figure 7). The nickel orifice plate is still used, but it defines only the bore instead of the entire chamber.

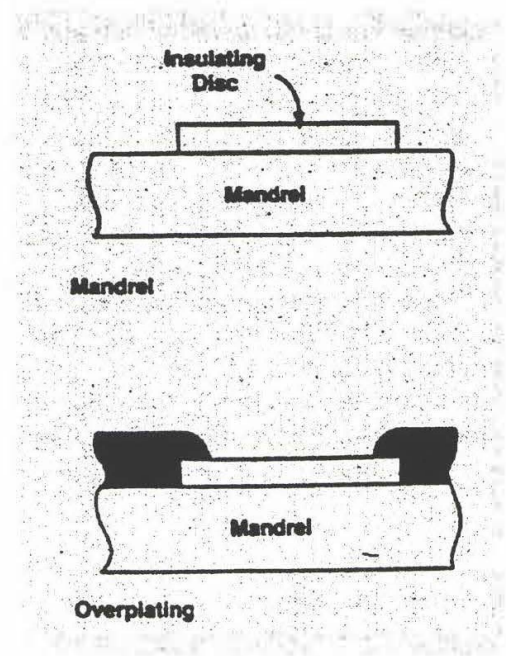

Figure 8. Orifice plate fabrication.

The process of creating the orifice plate is also unique in that it involves electroforming nickel on a stainless steel substrate called a mandrel that has patterned PECVD silicon nitride "buttons". The converging nozzle shape is created by the isotropic growth of the nickel film while the exit bore is determined by the amount of overplating onto the top of the nitride disc (figure 8).

As in the TIJ 1.0 process, ink feeds through the chip via a slot created by an abrasive sand drill. The rough edge created by the drilling process can be seen in the foreground of figure 7. Print quality improves dramatically when $300 \mathrm{dpi}$ architectures are employed (figure 9).

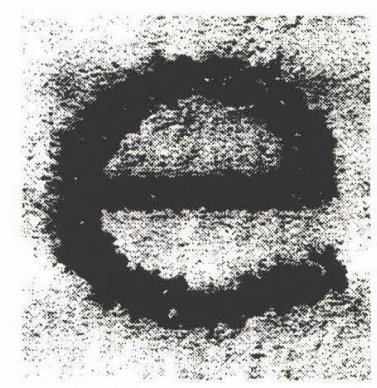

Figure 9. 300 dpi TIJ 2.0 character

\section{TIJ 2.5}

As the number and density of nozzles rose, it became increasingly difficult to interconnect the pen to the printer. Previous generations required a separate pad for each firing resistor. When this was no longer practical, a three mask NMOS process was integrated into the printhead (figure 10 on next page).A row and column addressing scheme is used to select the resistor to be fired. This reduces the pad count by a factor of one over the square root of the number of pads needed in the direct drive scenario (figure 11).

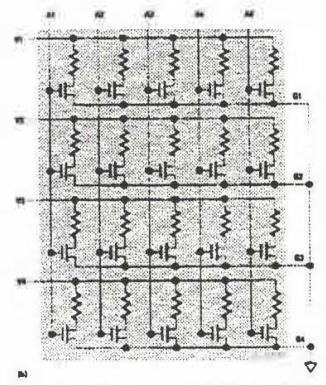

Figure 11. Row and column matrix addressing for TIJ 2.5

While much of the thin film set is unchanged, evolution of the firing chamber architecture is taking place. Smaller, better defined drops emerge from TIJ 2.5 pens than their predecessors.

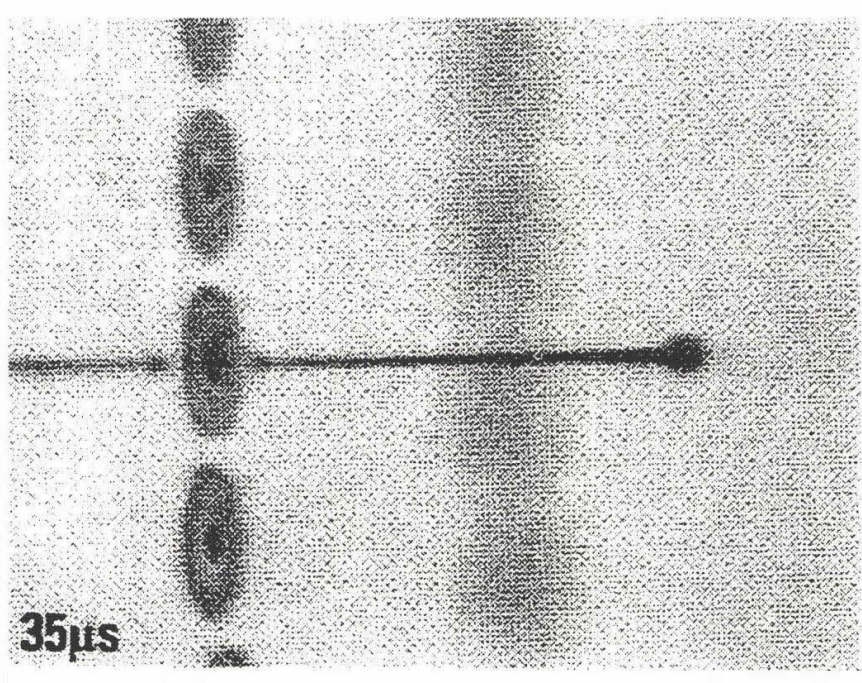

Figure 12. TIJ 2.5 drop ejection at thirty-five microseconds. 


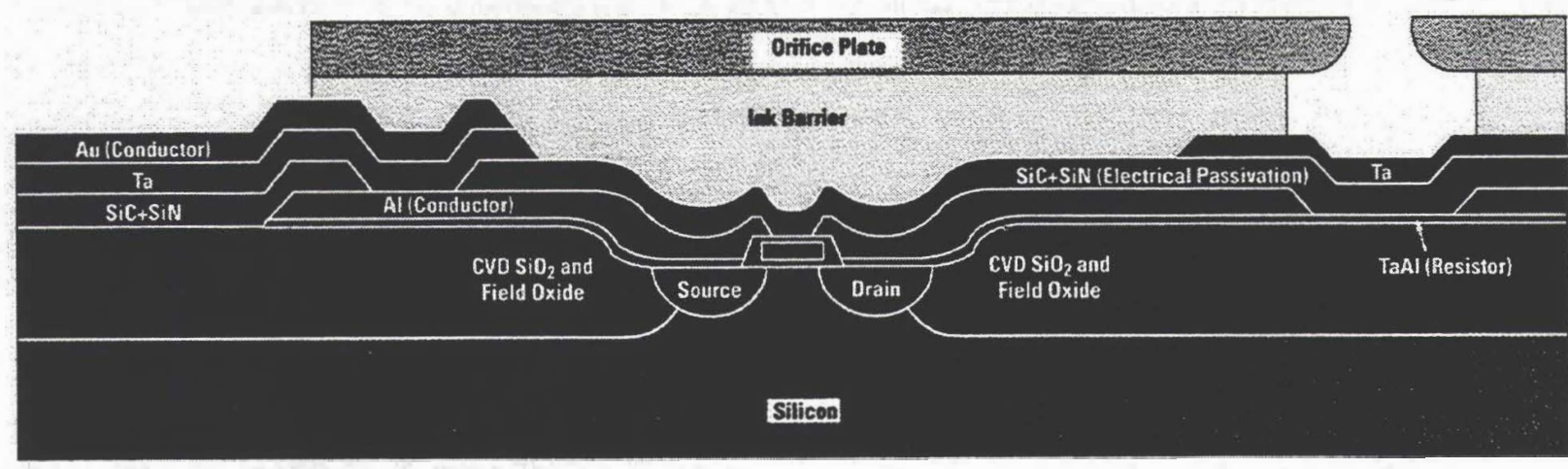

(c)

Figure 10. TIJ 2.5 thin-film cross section.

TIJ 3.0

The current generation of TIJ printheads utilizes TIJ 2.5 silicon but substitutes a laser ablated orifice in the flex circuit for the electroformed orifice. Laser ablation enables arrays of high density, high aspect ratio converging nozzles. For the first time, ink feeds over the sawed edge of the chip rather than through a drilled slot. This conserves expensive silicon die area.

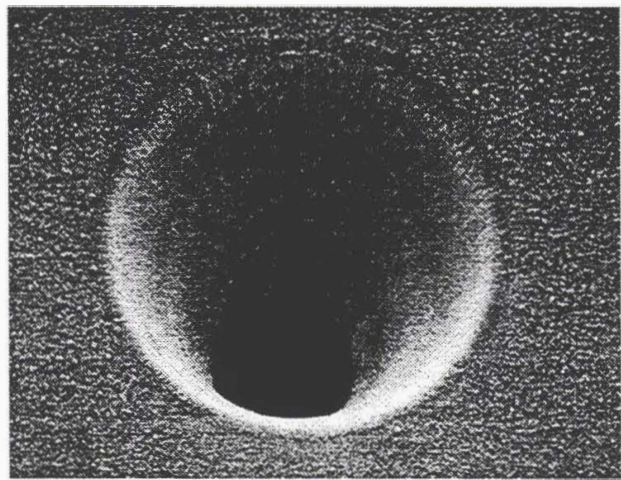

Figure 13. Laser ablated TIJ 3.0 orifice.

\section{FUTURE TRENDS}

The thermal inkjet market continues to grow at an astounding rate as innovations are brought into manufacturing. It is interesting to project the path into the future for key metrics of inkjet performance. Two notable parameters are the drop weight and the total nozzles per pen (figures 14 and 15). Drop weight or volume is important because the focus of development is increasingly on image quality as opposed to print quality. Inkjet technology is beginning to move beyond text applications into photographic quality images. The threshold line on the graph represents the minimum drop that the human eye can perceive. While this line varies depending interactions of the ink, media, and printer, it is clear that inkjet is rapidly approaching this regime. For drop volumes below this line, photographic quality images are possible since the observer will not perceive individual dots. Nozzle density goes hand-in-hand with advancements in volume since the print engine must be able to place the smaller drops at the appropriate intervals. This metric is also on course in the advancement of the technology rising from $96 \mathrm{dpi}$ in TIJ 1.0 to $600 \mathrm{dpi}$ in the TIJ 3.0 family.

\section{Inkjet Dropweight Evolution}

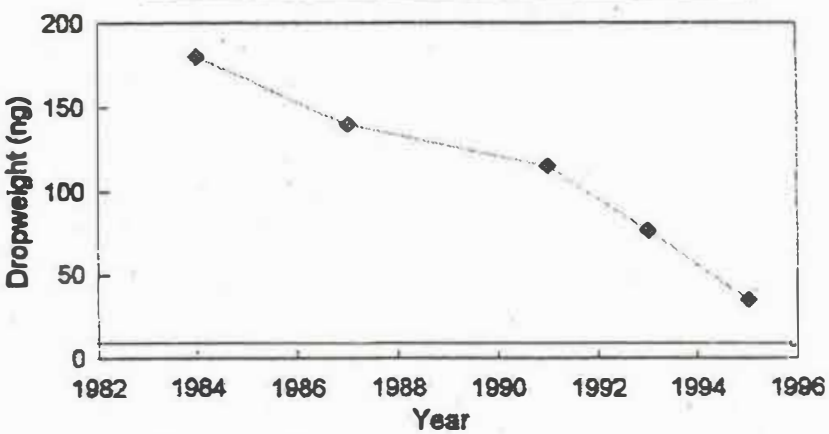

Figure 14. Inkjet drop weight versus time.

Total nozzle count has a pragmatic justification - as the drop volume decreases, the number and/or rate of firings must be increased to maintain the throughput of the printer (pages/minute). The rise in both nozzle count and firing frequency has enabled higher throughput despite the decreasing drop volume.

\section{Inkjet Nozzle Count Evolution}

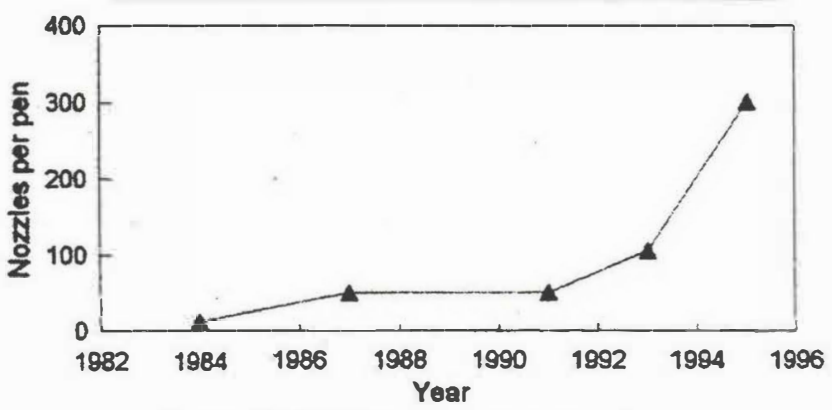

Figure 15. Inkjet nozzle count versus time.

\section{CONCLUSIONS}

While impressive progress has been made in thermal inkjet technology, the future is brighter still (figure 16 ). The competitive marketplace and wide acceptance of inkjet printing is driving innovation on many fronts. Ever higher levels of functionality, performance and speed are the expectations of a growing customer base. 


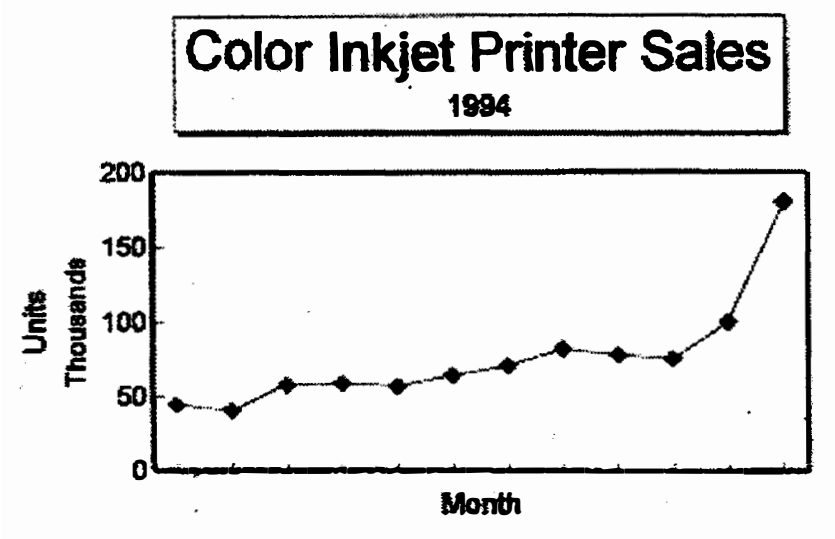

Figure 16. Color Inkjet sales for 1994.

\section{REFERENCES}

1) Allen, Ross R., Meyer, John D., Knight, William R., "Thermodynamics and Hydrodynamics of Thermal Ink Jets", Hewlett-Packard Joumal, May 1985, pages 21- 27

2) Bhaskar, Eldurkar V., Aden, J. Stephen, "Development of the Thin-Film Structure of the ThinkJet Printhead", Hewlett-Packard Journal, May 1985, pages 27-33

3) Siewell, Gary L., Boucher, William R., McClelland, Paul H., "The ThinkJet Orifice Plate: A Part With Many Functions", Hewlett-Packard Journal, May 1985, pages 33-37

4) Askeland, Ronald A., Childers, Winthrop D., Sperry, William R., "The Second-Generation Thermal InkJet Structure", Hewlett-Packard Journal, August 1988, pages 28-31

5) Buskirk, William A., Hackleman, David E., Hall, Stanley T., Kanarek, Paula H., Low, Robert N., Treuba, Kenneth E.., Van de Poll, Richard R., "Development of a High-Resolution Thermal Inkjet Printhead", Hewlett-Packard Journal, October 1988, pages 55-61.

6) Bohórquez, Jaime H., Canfield, Brian P., Courian, Kenneth J., Drogo, F., Hall, Corrina A.E., Holstun, Clayton L., Scandalls, Aneesa R., Shepard, Michele E., “ Laser-Compatible Inkjet Text Printing", Hewlett- Packard Journal, February 1994, pages 9-17

7) Aden, J. Stephen, Bohórquez, Jaime H., Collins, Douglas M., Crook, M. Douglas, Garcia, André, Hess, Ulrich E., "The Third Generation HP Thermal Inkjet Printhead", Hewlett-Packard Journal, February 1994, pages 41-45. 